\title{
Author Correction: Unprecedented rains decimate surface microbial communities in the hyperarid core of the Atacama Desert
}

\author{
A. Azua-Bustos $\mathbb{D}^{1,2}$, A. G. Fairén $\mathbb{D}^{1,3}$, C. González-Silva ${ }^{4}$, C. Ascaso $\mathbb{D}^{5}$, D. Carrizo $\mathbb{D}^{1}$, \\ M. Á. Fernández-Martínez ${ }^{1}$, M. Fernández-Sampedro ${ }^{1}$, L. García-Descalzo ${ }^{1}$, M. García- \\ Villadangos $^{1}$, M. P. Martin-Redondo ${ }^{1}$, L. Sánchez-García $\mathbb{D}^{1}$, J. Wierzchos $\mathbb{D}^{5}$ \& V. Parro $\mathbb{D}^{1}$ \\ Correction to: Scientific Reports https://doi.org/10.1038/s41598-018-35051-w, published online 12 November \\ 2018
}

This Article contains typographical errors in the Results section where,

"Massive parallel sequencing of $16 \mathrm{~S}$ ribosomal RNA gene amplicons showed that more than $60 \%$ of the sequences found in the lagoons belonged to only four main OTUs (Operational Taxonomical Units), specifically to the Class Gammaproteobacteria: Halomonas (found worldwide ${ }^{20}$ ), Marinimicrobium, Marinobacter and Acinetobacter (Table 1). A decrease in biodiversity is observed as the salinity of the lagoons increase (Table 1), revealing the higher salinity tolerance of Marinimicrobium and Marinobacter species compared to that of Halomonas and Acinetobacter species here reported."

should read:

"Massive parallel sequencing of 16S ribosomal RNA gene amplicons showed that more than $60 \%$ of the sequences found in the lagoons belonged to only four main OTUs (Operational Taxonomical Units), specifically to the Class Gammaproteobacteria: Halomonas (found worldwide ${ }^{20}$ ), Marinimicrobium, Marinobacter and Acinetobacter (Table 2). A decrease in biodiversity is observed as the salinity of the lagoons increase (Table 2), revealing the higher salinity tolerance of Marinimicrobium and Marinobacter species compared to that of Halomonas and Acinetobacter species here reported."

(i) Open Access This article is licensed under a Creative Commons Attribution 4.0 International License, which permits use, sharing, adaptation, distribution and reproduction in any medium or format, as long as you give appropriate credit to the original author(s) and the source, provide a link to the Creative Commons license, and indicate if changes were made. The images or other third party material in this article are included in the article's Creative Commons license, unless indicated otherwise in a credit line to the material. If material is not included in the article's Creative Commons license and your intended use is not permitted by statutory regulation or exceeds the permitted use, you will need to obtain permission directly from the copyright holder. To view a copy of this license, visit http://creativecommons.org/licenses/by/4.0/.

(c) The Author(s) 2019

${ }^{1}$ Centro de Astrobiología (CSIC-INTA), 28850, Madrid, Spain. ${ }^{2}$ Instituto de Ciencias Biomédicas, Facultad de Ciencias de la Salud, Universidad Autónoma de Chile, Santiago, Chile. ${ }^{3}$ Department of Astronomy, Cornell University, Ithaca, 14853, NY, USA. ${ }^{4}$ Facultad de Ciencias, Universidad de Tarapacá, Arica, Chile. ${ }^{5}$ Museo Nacional de Ciencias Naturales (CSIC), 28006, Madrid, Spain. Correspondence and requests for materials should be addressed to A.A.-B. (email: aazua@cab.inta-csic.es) or A.G.F. (email:agfairen@cornell.edu) 